\title{
A supplier selection using a hybrid grey based hierarchical clustering and artificial bee colony
}

\author{
Farshad Faezy Razi*
}

Department of Industrial Management, Semnan Branch, Islamic Azad University, Semnan, Iran

\begin{tabular}{l}
\hline C H R O N I C L E \\
\hline Article history: \\
Received October 15, 2013 \\
Received in revised format \\
March 2 2014 \\
Accepted May 1, 2014 \\
Available online \\
May 72014 \\
\hline Keywords: \\
Grey Relational Analysis \\
Hierarchical Clustering \\
Artificial Bee Colony \\
Evolutionary Optimization \\
Algorithms \\
Supplier Selection \\
\hline
\end{tabular}
A B S T R A C T

\begin{abstract}
Selection of one or a combination of the most suitable potential providers and outsourcing problem is the most important strategies in logistics and supply chain management. In this paper, selection of an optimal combination of suppliers in inventory and supply chain management are studied and analyzed via multiple attribute decision making approach, data mining and evolutionary optimization algorithms. For supplier selection in supply chain, hierarchical clustering according to the studied indexes first clusters suppliers. Then, according to its cluster, each supplier is evaluated through Grey Relational Analysis. Then the combination of suppliers' Pareto optimal rank and costs are obtained using Artificial Bee Colony meta-heuristic algorithm. A case study is conducted for a better description of a new algorithm to select a multiple source of suppliers.
\end{abstract}

\section{Introduction}

A supply chain includes all activities associated with the flow and transformation of products and services from raw material through to the end customer. It includes many of the activities connected to each other. This flow begins with the supplier of raw materials and continues with component and parts suppliers, assemblers, manufacturers, distributors and end customers (Wangphanich, 2010). Effective supply chain management is an effective way to improve the performance of the organization and to have its competitive advantage in the global business environment. Supply chain has always been challenged by customer's growing and diverse demand, modern advances in communications technology, information systems and the question of competition and these limitations have created significant opportunities for looking for appropriate methods for supplier selection. Logistics is a decisive and essential activity for all businesses and it significantly influences on the financial operations and competitiveness in most organizations. In such circumstances, the

\footnotetext{
* Corresponding author

E-mail addresses: farshadfaezy@yahoo.com (F. Faezy Razi) 
issue of outsourcing is extremely important and this is why most firms are now devoting more resources to outsource activities and to enhance their competitive advantage. The most important decision for buying and procurement is to select the right supplier for outsourcing (Saen, 2009). In the logistics literature, two primary approaches exist for selecting suppliers. Some scholars believe in considering suppliers just as vendors (Shine, 2000) because of various reasons such as lower expenses, higher quality and reliability, and better motivations. In contrast, another group of logistics experts, such as De Boer et al. (1998) believe in multiple sourcing in supply chain. According to the latter group, the main advantage of multiple sourcing is because of the reduction of the purchasing risk degree. In this paper, we propose a new model for supplier selection problem where candidate suppliers for clustering are clustered according to hierarchical clustering method. After that, Grey Relational Analysis (GRA) evaluates each cluster of suppliers and ultimately a two-objective mathematical programming model is designed to select the combination of Pareto optimal and cost, and Pareto optimal solution obtains through Multiple Objective Artificial Bee Colony. This paper proceeds as follows: Literature review is studied in the second part of the paper. In the third part, the factors considered in the selection of suppliers are provided. In the fourth part, Grey Relational Analysis (GRA) is explained. Fifth part discusses the hierarchical clustering method. Multi-objective optimal algorithm of Artificial Bee Colony is explained in sixth part. Part seven describes a new approach for the supplier selection. The case study and conclusions are presented in Sections 8 and 9.

\section{Literatures}

There are literally various approaches for supplier selection problem and most of these models utilize mathematical modeling techniques for selecting the best supplier. Garfamy (2006) used data envelopment analysis (DEA) approach in evaluating the overall performances of suppliers on multiple criteria based on TCO concept. Bayrak et al. (2007) utilized an algorithm based on calculating fuzzy suitability indices for the efficient vendor alternatives. Tsai (2009) presented a procedure for supplier evaluation by incorporating fuzzy set theory into the evaluation process to handle the qualitative attributes in the problem and applied a mathematical ranking method to convert the qualitative attributes into crisp score. Saen (2009) proposed a new pair of nondiscretionary factors-imprecise DEA models for selecting the best suppliers in the presence of nondiscretionary factors and imprecise data. Wu and Blackhurst (2009) proposed a supplier evaluation and selection methodology based on an extension of DEA method, which can evaluate suppliers, very effectively based on price, proprietary design partnerships, quality and delivery performance. Ravindran et al. (2010) developed a supplier selection model incorporating supplier risk and applied it to a real-world case study and developed two different kinds of risk models, value-at-risk (VaR) and miss-the-target (MtT) for supplier selection problem. Ku et al. (2010) used an integrated fuzzy goal programming (FGP) as well as fuzzy analytic hierarchy process (FAHP) for global supplier selection problem. Yücenur et al. (2011) proposed a model for selecting of the global supplier by analytical hierarchy process (AHP) and analytical network process (ANP) based on linguistic variable weight by considering four criteria including service quality, cost, risk factors and supplier's characteristics. Hammami et al (2012) developed a mixed integer programming model for a supplier selection problem in an international context. Li et al. (2012) used the Axiomatic Fuzzy Set clustering (AFS) method and FAHP model as well as Technique for Order Preference by Similarity to Ideal Solution (TOPSIS) for supplier evaluation and selection. Tidwell and Sutterfield (2012) examined quality function deployment (QFD) for supplier selection in consumer products Sector based on six criteria, namely; quality, sustainability, innovation, responsiveness and green initiatives. Rezaei and Ortt (2012) developed a new approach to supplier segmentation, which considers the various variables used in existing literature to segment suppliers. Bali et al. (2013) used intuitionistic fuzzy set (IFS) and grey relational analysis (GRA) for green supplier selection. There were eight criteria: service quality, green image, use of green materials, pollution/waste control in production, green product, distribution, reverse logistics and green design or R\&D. Deng et al. (2014) proposed a methodology 
for integrated product line design and supplier selection. Their model is based on Multi-objective optimization as well as non-dominated sorting genetic algorithm II (NSGA II). Jadidi et al. (2014) designed a multi-objective optimization problem (MOOP) where minimization of price, rejects and lead-time were considered as three objectives using TOPSIS, weighted goal programming, Min-max goal programming and weighted max-min model for supplier selection problem. Guo et al. (2014) presented a semi-fuzzy support vector domain description (semi-fuzzy SVDD) for supplier selection problem. Their model was based on artificial intelligence techniques. Kar (2014) proposed an approach for group decision support system for the supplier selection problem by integrating FAHP for group decision making and fuzzy goal programming for discriminant analysis. A summary of the conducted studies in the context of Supplier selection is presented in Table 1 as follows.

Table 1

A summary of the previous studies on maintenance selection

\begin{tabular}{|c|c|c|c|c|}
\hline No. & Decision Model/Method & Decision Problem & Decision Conditions & Researcher(s) \\
\hline 1 & DEA & Ranking & Deterministic & Garfamy, 2006 \\
\hline 2 & Fuzzy Supplier Selection Algorithm & Ranking & Fuzzy Condition & Bayrak et al., 2007 \\
\hline 3 & Fuzzy Set Theory & Ranking & Fuzzy Condition & Tsai, 2009 \\
\hline 4 & Imprecise DEA & Ranking & Non Deterministic & Saen, 2009 \\
\hline 5 & DEA & Ranking & Deterministic & Wu \& Blackhurst, 2009 \\
\hline 6 & Risk Modeling & Optimization & Non Deterministic & Ravindran et al., 2010 \\
\hline 7 & fuzzy goal programming (FGP), FAHP & Ranking Optimization & Fuzzy Condition & Ku et al., 2010 \\
\hline 8 & Fuzzy logic, Fuzzy AHP, Fuzzy ANP & Ranking & Fuzzy Condition & Yucenur et al., 2011 \\
\hline 9 & Mixed Integer Programming Model & Optimization & Deterministic & Hammami et al., 2012 \\
\hline 10 & AFS, FAHP, TOPSIS & Clustering, Ranking & Fuzzy Condition & Li et al., 2012 \\
\hline 11 & QFD & Ranking & Deterministic & Tidwell, 2012 \\
\hline 12 & Segmentation & Clustering & Non Deterministic & Rezaei \& Ortt, 2012 \\
\hline 13 & intuitionistic fuzzy set, GRA & Ranking & Fuzzy Condition & Bali, 2013 \\
\hline 14 & Multi-objective optimization, NSGA II & Optimization & Non Deterministic & Deng et al., 2014 \\
\hline 15 & Goal Programming, TOPSIS & Optimization, Ranking & Deterministic & Jadidi et al., 2014 \\
\hline 16 & Multi-echelon inventory system & Optimization & Deterministic & Guo \& Li, 2014 \\
\hline 17 & AHP & Ranking & Fuzzy Condition & Kar, 2014 \\
\hline
\end{tabular}

\section{Factors considered in selecting suppliers}

According to De Boer (1998), the supplier selection is a process with four main steps, namely definition, model formulation, determination of qualified suppliers and selection. The most important issues that should be considered in this process include:

- Number and nature of the criteria: Decision-making process for supplier selection is complex in nature $(\mathrm{Ku}, 2010)$. These criteria can be quantitative or qualitative and are often in conflict with each other.

- Procurement strategy: There are two main strategies in connection with procurement:

- Providing from a source: a supplier can meet all its needs from a single buyer.

-Providing from multiple sources: based on this strategy, several suppliers are used to reduce the degree of purchasing risk.

- Decision rules: Approaches to the selection of a supplier can result in a satisfactory or nonsatisfactory answer. In most circumstances, metaheuristics approaches analyze the supplier selection problem by Pareto optimal solutions (De Boer, 1998).

- Number of decision makers: In the supply chain literature, the basic assumption is that there are more than one single decision maker. Webster and Weiner believe that logistics issue is a complex process and therefore it is necessary to use various staff and experts in decision making process.

- Degree of reliability: In the logistics problem, decision-making process is often accompanied by uncertainty. However, supplier selection models have different points of view about the issue of uncertainty. 


\section{Grey Relational Analysis}

Gray represents unknown or incomplete information and the Gray theory was proposed by Deng in 1982 (Deng, 1989). Using this theory, Deng presented a model to analyze the systems with uncertain and incomplete information. This model is often applied for predicting decision making in industrial engineering and management sciences. In theory, as illustrated in Fig. 1, dark and light colors represent ambiguous and obvious information, respectively. Meanwhile, the black color represents the status of the systems in which, there are no structure, parameters and absolutely certain characteristics of knowledge. White color represents entirely obvious information. Colors between white and black represent ambiguous systems. Economic and social systems and climate are in this category. The most important functional fields covered by gray theory include systems analysis, data processing, modeling, forecasting, decision-making and control( $\mathrm{Wu}, 2002)$.

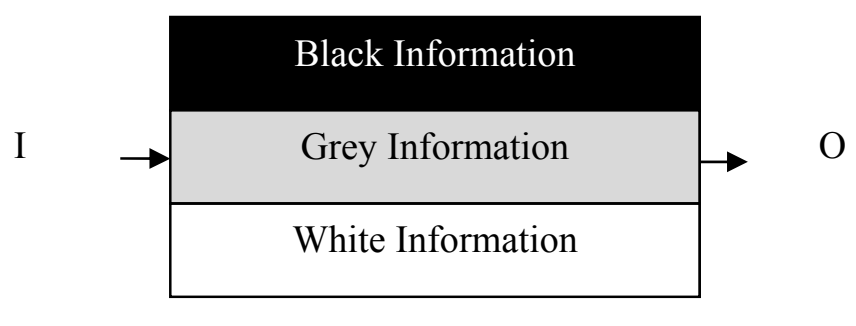

Fig. 1. A gray system

According to Fig. 1 in a gray system, some elements of the system are known and others are unknown. Grey relation analysis is a considerable subject of gray theory and it is considered as multiple criteria decision-making (MCDM) issues. In such situations, there is a complex relationship between various factors. Gray relation analysis is a simple decision analysis process. Grey relation analysis model measures the impact of the changes between two systems or two components of a system, in unit of time. Therefore, gray relation studies the unknown relationships between objects, components and system behavior. Due to the uncertainty in the supplier selection process, gray analysis is an appropriate method. Grey relation analysis algorithm for supplier selection problem, involves four basic steps which are as follows:

\section{- Step 1: Gray relation definition}

In this step, the total value of each strategy is processed, based on a comparable sequence. In this process, normalization approach is evaluated to prevent neglecting a number of indicators. Let $m$ be the number of alternatives and $n$ be the number of attributes, reference and comparison sequence vectors are stated in Eq. (1) and Eq. (2), respectively.

$X_{0}=\left(x_{01}, x_{02}, \ldots, x_{0 n}\right)$,

$X_{i}=\left(x_{i 1}, x_{12}, \ldots, x_{i n}\right)$,

Let $y_{i}$ be the main vector of index value for each option. If a specific adaptive sequence is more important than another, it is assigned a higher score of gray relation. Let $m$ be the alternative and $n$ be the attribute for the $i^{\text {th }}$ alternative, vector $Y_{i}$ is given as described by Eq. (3).

$Y_{i}=\left(y_{i 1}, y_{\left.i 2, \ldots, y_{i n}\right)}\right.$,

In Eq. (3), $y_{i j}$ is the value of the $i^{\text {th }}$ attribute of $j^{\text {th }}$ alternative. Compatible sequences vector $x_{i j}=\left(x_{i 1}, x_{i 2}\right.$, $\left.\ldots, x_{i n}\right)$ is calculated using Eqs. (4-6). Eq. (4) can be used for indexes with better features. 


$$
X_{i j}^{*}=\frac{x_{i}(j)-\min x_{i}(j)}{\max x_{i}(j)-\min x_{i}(j)^{\prime}}
$$

For index $\mathrm{X}_{\mathrm{ij}}$ with the criterion of "the less the better", Eq. (5) can be used.

$$
X_{i j}^{*}=\frac{\max x_{i}(j)-x_{i}(j)}{\max x_{i}(j)-\min x_{i}(j)^{\prime}}
$$

Finally, for the indexes, which are closer to the nominal criterion, Eq. (6) can be used as follows,

$$
X_{i j}^{*}=\frac{\left|x_{i}(j)-x_{o b}(j)\right|}{\max x_{i}(j)-x_{o b}(j)}
$$

\section{- Step 2: definition of reference sequence}

To identify the relationship between comparable series, a reference sequence is created and $X_{0}=\left(x_{01}\right.$, $\left.x_{02} \ldots x_{0 n}\right)$ is defined based on that sequence and all values are scaled in the range $\left[\begin{array}{ll}0 & 1]\end{array}\right.$. If the attribute $x_{i j}$ processed through the gray relationships is equal to one or close to that number, then the value of the attribute $i$, will influences $j^{\text {th }}$ alternative. This means that, if the strategy approaches more closely to one, it will have more chances to be selected as the best option. So, the reference sequence functions are described according to the Eq. (7),

$X_{0}=\left(x_{01}, X_{02}, \ldots, X_{0 n}\right)=(1,1, \ldots, 1)$,

Step 3: Calculating confidence intervals for gray relations

The confidence interval is calculated for gray relation, based on the Eq. (8).

$\mathrm{Y}\left(\mathrm{x}_{0 \mathrm{j}}, \mathrm{x}_{\mathrm{ij}}\right)=\frac{\Delta_{\min +\xi \Delta_{\max }}}{\Delta_{i j+\xi} \Delta_{\max }}$,

$\Delta_{\mathrm{ij}}$ can be calculated According to Eq. (9) as follows,

$\Delta_{\mathrm{ij}}=\left|\mathrm{x}_{0 \mathrm{j}}-\mathrm{x}_{\mathrm{ij}}\right|$,

where $\Delta \min$ and $\Delta \max$ are calculated based on Eq. (10) and Eq. (11), respectively.

$\Delta_{\min }=\min \left\{\Delta_{i j}, i=1, \ldots, m, j=1, \ldots, n\right\}$,

$\Delta_{\max }=\max \left\{\Delta_{i j}, i=1, ., m, j=1, \ldots, n\right\}$,

- Step 4: Calculating the Gray Relation Score

Eq. (12) is used to calculate the gray relation score as follows,

$\Gamma(\mathrm{x} 0, \mathrm{xi})=\sum_{j=1}^{n} w_{j} \times \mathrm{Y}\left(\mathrm{x}_{0 \mathrm{j}}, \mathrm{x}_{\mathrm{ij}}\right)$.

Dedicated weights to criteria by decision makers are determined using methods such as AHP and ANP with respect to the relations between criteria.

\section{Hierarchical Clustering}

Deterministic clustering methods generally fall into two categories: hierarchical and denotative. Hierarchical methods can be classified into two categories: merging and splitting methods. Merging method firstly considers each object as a separate cluster, after that the clusters are merged in 
clustering process to achieve a single cluster. Splitting methods use a reverse mechanism. First, all objects are considered as a single cluster, and then the cluster splits into several clusters in the clustering process. Average Linkage method, presented by Jain and Dubes (1988), is one of the hierarchical clustering techniques. This considers the average of all distances between pairs of points of two groups for calculating the distance between two groups. Suppose $C_{k}, C_{J}, C_{i}$ are three clusters. The distance between clusters $C_{\mathrm{k}}$ with $\boldsymbol{C}_{\boldsymbol{i}} \boldsymbol{C}_{\boldsymbol{j}}$ is calculated by Eq. (13).

$\mathrm{d}\left(\mathrm{C}_{\mathrm{k}}, \mathrm{C}_{\mathrm{i}} \mathrm{U} \mathrm{C} \mathrm{C}_{\mathrm{j}}\right)=\frac{\left|C_{i}\right|}{\left|C_{i}\right|+\left|C_{j}\right|} d\left(C_{k}, C_{i}\right)+\frac{\left|C_{j}\right|}{\left|C_{i}\right|+\left|C_{j}\right|} d\left(C_{k}, C_{i}\right)$,

In Eq. (13), $d$ represents the distance, $C_{i}$ is the number of objects in groups $i$ and $\left|C_{j}\right|$ is the number of the objects of group $j$.

\section{Artificial Bee Colony}

Bee Colony based algorithms are probable population-based meta-heuristic algorithms, which belong to the group of collective intelligence algorithms. These algorithms are inspired by the behavior of honey bee colony. Colony of bees has many features that can be applied as a model of collective intelligence behavior. These features include Nectar Exploration, Food Foraging and the Labor Division. The role of bee colony is to find food sources. These food sources contain the highest possible amount of nectar. Based on the role of bees in foraging, they are divided into two categories:

- Unemployed Foragers: These kinds of bees have no information about foraging. They just seek for food near the hive or work inside the hive.

- Employed Forgers: These Bees explore and exploit food sources, then; they memorize the place of these resources. Next, they make other bees aware of resource location by Honey Bee Waggle Dance.

Foraging is based on two strategies:

- Food sources exploring: When a bee finds a source of rich food, it shows the place to the Onlooker bees in the hive by Waggle Dance, thereby the bees that see these actions, become employed foragers and begin to look for that food source.

- Resource exploitation: employed bees, calculate the amount of food sources and make decision about the exploitation. If there is sufficient amount of nectar, exploitation proceeds, otherwise the source is released.

The relationship between natural and artificial bee colonies is presented in Table 2.

\section{Table 2}

The relationship between natural and artificial bee colony

\begin{tabular}{cc}
\hline Natural Bee Colony & Artificial Bee Colony \\
Food Resource & Answer \\
Amount of Nectar & Objective Function \\
Observer Bees & Exploitation \\
Employed Bees & Exploration \\
\hline
\end{tabular}

\section{A new framework for supplier selection based on multiple source strategy}

This paper provides a comprehensive framework based on multi-source procurement strategy for supplier selection problem. As previously mentioned, other methods and models are based on a single 
source strategy for supplier selection. Methods and models proposed for multi-source procurement strategy put suppliers in a cluster and then; rank them. However, this study proposed methodology classifies each supplier in several clusters by hierarchical supplier clustering and then each supplier is evaluated according to its cluster. The main steps of discussed methodology are illustrated in Fig. 2.

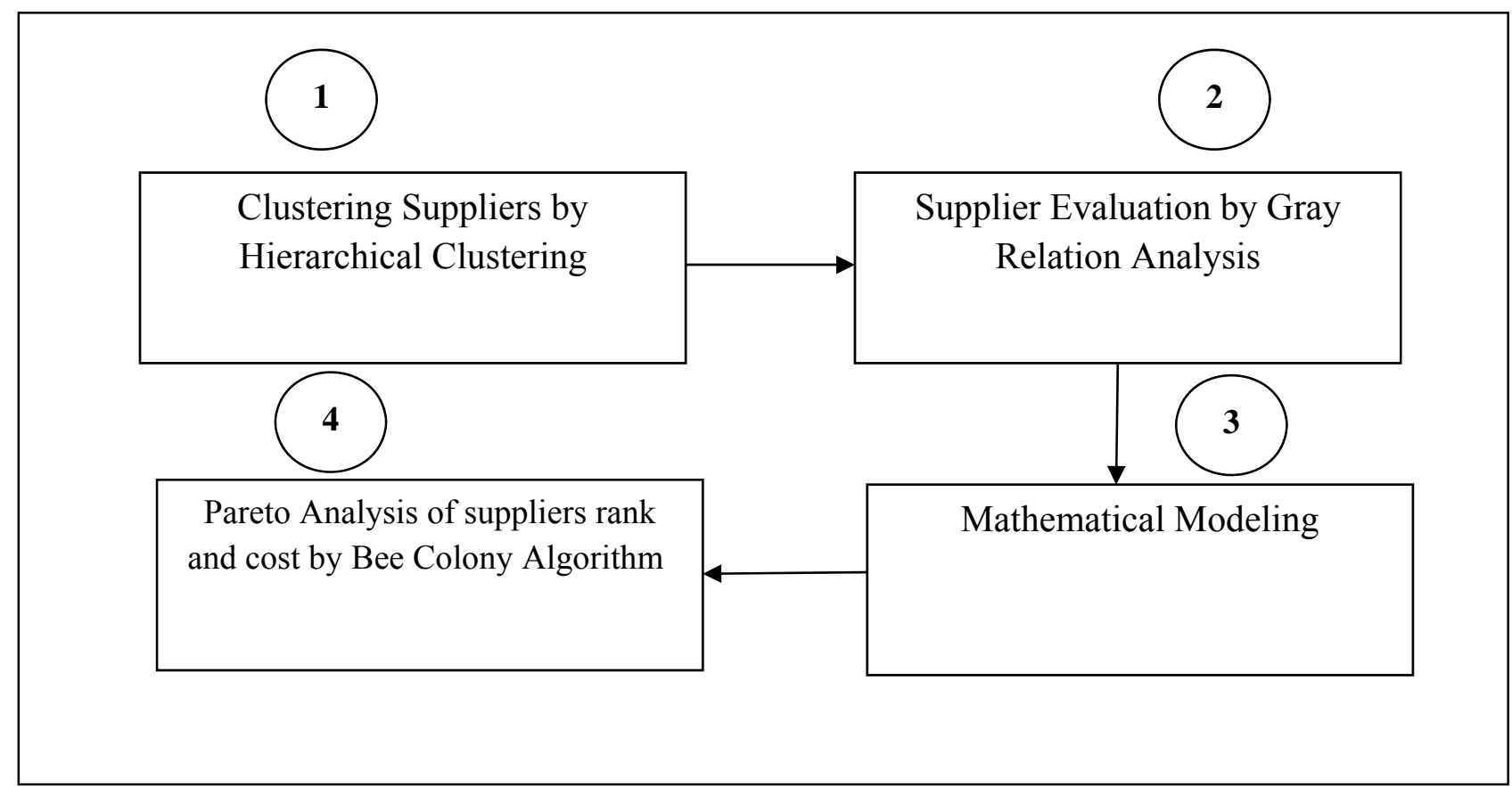

Fig. 2 A framework for supplier selection

The main steps of the framework presented in Fig. 2 can be explained as follows;

- Clustering: in the first step, suppliers are clustered using hierarchical clustering.

- Evaluation: In this step, suppliers are evaluated separately in each cluster.

- Designing: In this step, a two-objective programming model is designed to select maximum rank and minimum cost Pareto as follows. Variables and parameters of this model are summarized in Table 3.

\section{Table 3}

Notations used in the mathematical model

\begin{tabular}{l|l}
\hline $\begin{array}{l}\text { Parameters } \\
W_{i}\end{array}$ & Number of Suppliers \\
\hline$R_{i}$ & Weight of Supplier $\mathrm{i}^{\text {th }}$. \\
$C_{i}$ & Cost of Supplier $\mathrm{i}^{\text {th }}$. \\
$B_{j}$ & Level of Demand for Supplier $\mathrm{i}^{\text {th }}$. \\
Decision variable & Total Demand \\
$X_{i}$ & The binary decision variable, which is 1 if Supplier i is selected, and otherwise is zero. \\
\hline
\end{tabular}

$$
\begin{aligned}
& \max z_{1}=\sum_{i=1}^{n} w_{i} x_{i}, \\
& \min z_{2}=\sum_{i=1}^{n} R_{i} x_{i},
\end{aligned}
$$


$\sum_{i=1}^{n} c_{i} x_{i} \leq b$

$x_{i} \in\{0,1\}$.

- Optimization: In this step, Pareto solution of two objects in the model are calculated and analyzed using Artificial Bee Colony.

\section{Case Study}

A case study is used to explain how to use the Grey based Hierarchy Clustering and Artificial Bee Colony algorithm. In this study, there are 20 suppliers and Criteria to assess suppliers including supplier credit (C1), distance (C2), Number of healthy goods that are received from suppliers (C3) percentage of orders that are received on time (C4). All attribute in the study are considered positive. When the distance indicator is positive, transportation income increases in the whole country by increasing distance of transport. This is defined as one the corporate social responsibilities in the organization mission statement. Therefore, it is aimed to select the best combination of suppliers with respect to the criteria described in Table 2. In this studied organization, there is a demand equal to 5000 units for items to be provided out of 20 suppliers. Input data are presented in Tables 4-5.

Table 4

The input data of problem

\begin{tabular}{|c|c|c|c|c|}
\hline Alternative & $\mathrm{C}_{1}$ & $\mathrm{C}_{2}$ & $\mathrm{C}_{3}$ & $\mathrm{C}_{4}$ \\
\hline S1 & 5 & 249 & 1200 & 0.9992 \\
\hline S2 & 10 & 643 & 1010 & 0.9984 \\
\hline S3 & 3 & 714 & 1150 & 0.9863 \\
\hline S4 & 6 & 1809 & 1190 & 0.9856 \\
\hline S5 & 4 & 238 & 1050 & 0.9925 \\
\hline S6 & 2 & 241 & 1220 & 0.9968 \\
\hline S7 & 8 & 1404 & 1250 & 0.9946 \\
\hline S8 & 11 & 984 & 1070 & 0.9834 \\
\hline S9 & 9 & 641 & 1020 & 0.9889 \\
\hline $\mathrm{S} 11$ & 16 & 251 & 1040 & 1 \\
\hline S12 & 14 & 567 & 1230 & 0.9843 \\
\hline S13 & 15 & 667 & 1260 & 0.9918 \\
\hline S14 & 13 & 967 & 1210 & 0.9989 \\
\hline S15 & 12 & 635 & 1240 & 0.9959 \\
\hline S16 & 17 & 795 & 1080 & 0.9872 \\
\hline S17 & 1 & 689 & 1090 & 0.9939 \\
\hline S18 & 18 & 913 & 1060 & 0.9991 \\
\hline S19 & 20 & 230 & 1030 & 0.9804 \\
\hline
\end{tabular}

Table 5

The total cost of each supplier

\begin{tabular}{cccccccccccc}
\hline No, & S1 & S2 & S3 & S4 & S5 & S6 & S7 & S8 & S9 & S10 \\
\hline Total Cost & 253 & 268 & 259 & 180 & 257 & 248 & 272 & 330 & 327 & 330 \\
\hline No, & S11 & S12 & S13 & S14 & S15 & S16 & S17 & S18 & S19 & S20 \\
\hline Total Cost & 321 & 329 & 281 & 309 & 291 & 334 & 249 & 216 & 290 & 350 \\
\hline
\end{tabular}

After standardizing the data using MATLAB software and Hierarchical Clustering algorithms, clustering result is illustrated in Fig. 3. Complete suppliers ranking results by gray relation analysis is considered in Table 6. 

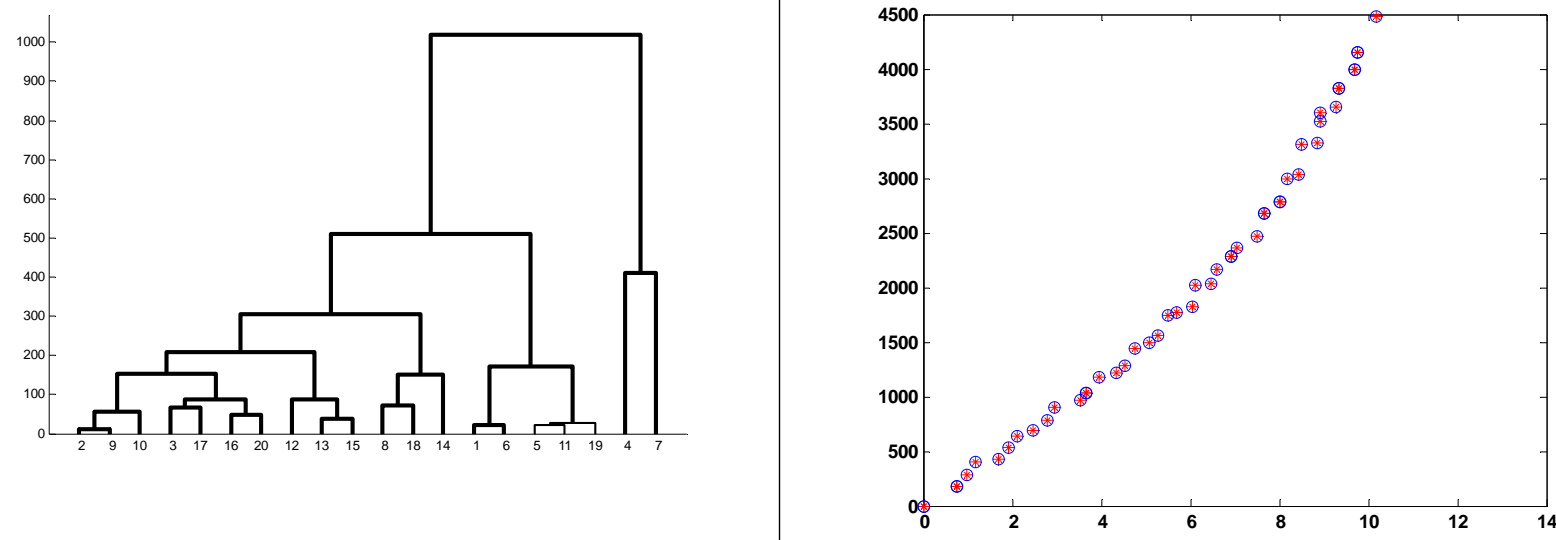

Fig. 3. Results of Suppliers hierarchical clustering

Fig. 4. Pareto model solutions by Artificial Bee Colony

Table 6

Ranking results of each cluster by gray relation analysis

\begin{tabular}{ccccccccccccc}
\hline No, & S1 & S2 & S3 & S4 & S5 & S6 & S7 & S8 & S9 & S10 \\
\hline Cluster & 5 & 1 & 2 & 6 & 5 & 5 & 6 & 4 & 1 & 1 \\
GRA & 0.8656 & 0.7461 & 0.7831 & 0.7586 & 0.4545 & 0.9239 & 0.6532 & 0.6825 & 0.9788 & 0.4121 \\
\hline No, & S11 & S12 & S13 & S14 & S15 & S16 & S17 & S18 & S19 & S20 \\
\hline Cluster & 5 & 3 & 3 & 4 & 3 & 2 & 2 & 4 & 5 & 2 \\
GRA & 0.5265 & 0.4138 & 0.9998 & 0.8826 & 0.5714 & 0.6541 & 0.4342 & 0.4168 & 0.4196 & 0.5515 \\
\hline
\end{tabular}

Zero-one two-objective programming model presented in this study is solved and the results are given in Fig. 4. Running time of the algorithm is 121.3631 seconds and adjusted parameters of the algorithm are as described in Table 7.

Table 7

Adjusted parameters in MATLAB to run the Artificial Bee Colony Algorithm

\begin{tabular}{ccc}
\hline No, & Parameter & Value \\
\hline 1 & Number of Bee & 100 \\
2 & Number of Food & Number of Bee/2 \\
3 & Maximum of Iteration & 100 \\
\hline
\end{tabular}

\section{Conclusion}

Decision Making for supplier selection and purchasing have been taken into consideration over the past two decades, systematically. Models presented in this field use different mathematical approaches to select the best supplier. Non-classical mathematical models for supplier selection in decision-making process consider more than one criterion. In inventory operation doctrine, determination of optimal amount of orders and optimal cost of inventory system is also an important issue that needs to be considered as supplier selection. This influences the outsourcing activities of organization. While most methods of supplier selection use multi attribute decision making methodology, multi-objective decision making (MODM) models are used to determine the optimal amounts of orders in logistics and supply chain literature. In this paper, effective criteria for supplier selection were determined according to multiple-source strategies in the field of logistics and supply chain. Suppliers are then clustered and each cluster is evaluated are ranked, subsequently. Although 
the methodology presented in this study has been used for supplier selection problem, but can be applied to all management issues with multi-criteria nature.

\section{References}

Bali, O., Kose, E., \& Gumus, S. (2013). Green supplier selection based on IFS and GRA. Grey Systems: Theory and Application, 3(2), 158-176.

Bayrak, M. Y., Celebi, N., \& Taşkin, H. (2007). A fuzzy approach method for supplier selection. Production Planning and Control, 18(1), 54-63.

Deng, S., Aydin, R., Kwong, C. K., \& Huang, Y. (2014). Integrated product line design and supplier selection: a multi-objective optimization paradigm. Computers \& Industrial Engineering, 70, 150158.

Garfamy, R. M. (2006). A data envelopment analysis approach based on total cost of ownership for supplier selection. Journal of enterprise information management, 19(6), 662-678. .

Guo, X., Zhu, Z., \& Shi, J. (2014). Integration of semi-fuzzy SVDD and CC-Rule method for supplier selection. Expert Systems with Applications, 41(4), 2083-2097.

Hammami, R., Frein, Y., \& Hadj-Alouane, A. B. (2012). An international supplier selection model with inventory and transportation management decisions. Flexible services and manufacturing journal, 24(1), 4-27.

Jadidi, O., Zolfaghari, S., \& Cavalieri, S. (2014). A new normalized goal programming model for multi-objective problems: A case of supplier selection and order allocation. International Journal of Production Economics, 148, 158-165.

Jain, A. K., \& Dubes, R. C. (1988). Algorithms for clustering data. Prentice-Hall, Inc.

Kar, A. K. (2014). Revisiting the supplier selection problem: An integrated approach for group decision support. Expert Systems with Applications, 41(6), 2762-2771.

Ku, C. Y., Chang, C. T., \& Ho, H. P. (2010). Global supplier selection using fuzzy analytic hierarchy process and fuzzy goal programming. Quality \& Quantity, 44(4), 623-640.

Li, Y., Liu, X., \& Chen, Y. (2012). Supplier selection using axiomatic fuzzy set and TOPSIS methodology in supply chain management. Fuzzy Optimization and Decision Making, 11(2), 147176.

Ravindran, A. R., Ufuk Bilsel, R., Wadhwa, V., \& Yang, T. (2010). Risk adjusted multicriteria supplier selection models with applications. International Journal of Production Research, 48(2), 405-424.

Rezaei, J., \& Ortt, R. (2012). A multi-variable approach to supplier segmentation. International Journal of Production Research, 50(16), 4593-4611.

Saen, R. F. (2009). A decision model for ranking suppliers in the presence of cardinal and ordinal data, weight restrictions, and nondiscretionary factors.Annals of Operations Research, 172(1), 177-192.

Shin, H., Collier, D. A., \& Wilson, D. D. (2000). Supply management orientation and supplier/buyer performance. Journal of Operations Management, 18(3), 317-333.

Tidwell, A., \& Sutterfield, J. S. (2012). Supplier selection using QFD: a consumer products case study. International Journal of Quality \& Reliability Management, 29(3), 284-294.

Tsai, W. C. (2009). Fuzzy measures of supplier evaluation under lean concepts. Journal of the Operational Research Society, 60(7), 1005-1011.

Wangphanich, P., Kara, S., \& Kayis, B. (2010). Analysis of the bullwhip effect in multi-product, multi-stage supply chain systems-a simulation approach. International Journal of Production Research, 48(15), 4501-4517.

Wu, T., \& Blackhurst, J. (2009). Supplier evaluation and selection: an augmented DEA approach. International Journal of Production Research,47(16), 4593-4608.

Yücenur, G. N., Vayvay, Ö., \& Demirel, N. Ç. (2011). Supplier selection problem in global supply chains by AHP and ANP approaches under fuzzy environment. The International Journal of Advanced Manufacturing Technology, 56(5-8), 823-833. 